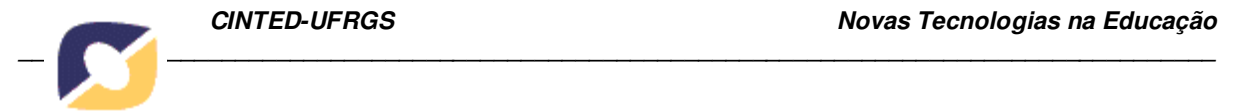

\title{
UMA APLICAÇÂO MULTIMIDIA PARA O ENSINO E APRENDIZAGEM DE SISTEMAS DE NUMERAÇÃO
}

Maria do Carmo Barbosa Trevisan - UNIFRA - mcbtrevisan@ hotmail.com

Gilse A. Morgental Falkembach - UNIFRA - gilsemf@terra.com.br

Vanilde Bisognin - UNIFRA - vanilde@ unifra.com

\section{RESUMO}

Neste trabalho tem-se como objetivo apresentar uma aplicação hipermídia educacional desenvolvida para o estudo de diferentes Sistemas de Numeração e das operações matemáticas, usando-se a simbologia de cada sistema. Além disso, a aplicação envolve a visualização de todo o processo de transformação das bases decimal, binária, octal e hexadecimal. A proposta metodológica foi centralizada no desenvolvimento de aplicações hipermídia, em que a aplicação foi projetada a partir dos recursos do Sistema de Autoria TOOLBOOK, versão 7.1.

PALAVRAS-CHAVE: sistemas de numeração, multimídia, agente pedagógico.

\begin{abstract}
This paper aims at presenting an hipermedia educational aplication, which was developed for the study of different Numeration Systems and mathematical operations, using the symbols of each system. In addition to this, the application implicates the visualization of the whole transformation process of the decimal, binary,octal and hexadecimal basis. The methodologic proposal was based on the development of hipermedia applications, considering that the application was developed with TOOLBOOK 7.1 System resources.
\end{abstract}

Key words: systems of numeration, multimedia, teaching staff. 


\section{INTRODUÇÃO}

As discussões e o desenvolvimento de novas tecnologias na educação, bem como o seu uso, vêm crescendo nos últimos anos. Resultados de diferentes pesquisas apontam que o seu uso colabora no desenvolvimento da capacidade cognitiva do educando e modifica a relação entre professor e alunos na sala de aula, fazendo com que o trabalho seja mais produtivo e, dessa forma, cria um ambiente que favorece a aprendizagem.

As Novas Tecnologias de Comunicação e Informação aplicadas à educação, segundo Falkembach (2003), constituem-se em um campo em expansão, o qual está voltado para a pesquisa e a criação de aplicações educacionais no formato digital; estratégias pedagógicas utilizadas na elaboração dessas aplicações e na interatividade e comportamento do aluno, frente a esse novo recurso didático.

\section{Segundo Dalabona (2005),}

No momento em que as Tecnologias de Informação e Comunicação revolucionam o mundo e invadem as escolas, a Educação pede uma nova proposta de trabalho. As Tecnologias de Informação e Comunicação afetam a maneira de compreender o mundo, as formas de viver, de conviver e os modos de fazer e de ser. (p. 207).

De acordo com Sancho (1998), o espaço escolar é, na atualidade, excessivamente baseado na cultura oral e no texto impresso, de modo que, incorporar ao seu cotidiano outras linguagens como a linguagem plástica, a gestual, a televisiva, a sinestésica, a teatral, a musical, a das novas tecnologias e outras, tem sido um desafio. É necessário que a escola olhe para o seu entorno e não desconsidere o que está acontecendo na sociedade em que está inserida. Hoje, é inegável que a sociedade está cada vez mais marcada por novas formas de comunicação e o acesso a essa gama de informações deve perpassar o espaço escolar.

A revolução tecnológica está formando a geração N (Network) de alunos, que cresceram usufruindo ambientes ricos em multimídia, com expectativas e visão de mundo diferente das gerações anteriores. Dessa forma com uma quantidade maior de 
informações propostas a essa nova geração se fazem necessários novos métodos e formas de aquisição do saber. Portanto preconizam-se formas de ensinar que privilegiem a aquisição de mecanismos, em que esses permitam descobrir, selecionar e utilizar os novos conhecimentos, assim como compreender e interpretar integralmente os fatos e os fenômenos. Essas mudanças caracterizam a Sociedade da Informação e do Conhecimento, as quais exigem uma reavaliação da estrutura educacional vigente e fazem surgir um novo paradigma educacional, não mais centrado no ensino, mas na aprendizagem. O modelo deve ser centrado no aluno-aprendiz, em suas necessidades, em seus objetivos e em seu ritmo de aprendizagem. A escola, como promotora de conhecimento, precisa oferecer diferentes formas de intervenções pedagógicas, no sentido de criar condições adequadas para a apropriação do conhecimento, por parte do aluno. Para esse novo paradigma, acredita-se que materiais educativos digitais podem contribuir, de forma efetiva, para o ensino e aprendizagem de conteúdos de matemática, conforme propomos neste trabalho.

Nesse sentido, o trabalho tem como objetivo apresentar uma aplicação hipermídia educacional, desenvolvida para o estudo de Sistemas de Numeração e das operações matemáticas nas bases decimal, binária, octal e hexadecimal, possibilitando a visualização dos processos envolvidos. A proposta metodológica foi centralizada no desenvolvimento de aplicações hipermídia.

Para projetar a aplicação, considerou-se que o processo de desenvolvimento inclui, tanto o funcionamento da aplicação, quanto os mecanismos pedagógicos, os quais que embasam uma aplicação de ensino e aprendizagem e os conceitos relevantes relacionados ao tema. A implementação foi feita via Sistema de Autoria.

\section{HIPERMÍDIA}

As aplicações hipermídia educacionais constituem a mais recente tecnologia para a integração e contextualização do saber, sendo, portanto, uma ferramenta poderosa nos processos de construção da aprendizagem. Atualmente, a informação acadêmica está disponível nos meios eletrônicos, por meio dos ambientes de aprendizagem, facilitando, ao aluno, a exploração do conteúdo de forma livre, segundo seu interesse, 
seu ritmo, estimulando o trabalho cooperativo, a comunicação e a aquisição do conhecimento. As aplicações hipermídia educacionais, por serem flexíveis e permitirem acesso às informações de forma não linear, dão ao aprendiz o controle sobre sua navegação.

A hipermídia é uma nova forma de gerenciar informações. Permite criar, alterar, excluir, compartilhar e consultar informações contidas em várias mídias, possibilitando o acesso às informações de forma não seqüencial, baseado no paradigma conexionista das ciências cognitivas. A hipermídia também possibilita criar aplicações educacionais atraentes e motivadoras, agregando o fascínio da multimídia ao aprendizado. Conforme definido por Falkembach (2001), Hipermídia $=$ Multimídia + Hipertexto, tal combinação de mídias, transmite as informações de várias formas, estimula diversos sentidos ao mesmo tempo e isso auxilia no processo de ensino e aprendizagem, pois a carga informativa é significativamente maior uma vez que, os apelos sensoriais são multiplicados, a atenção e o interesse do aluno são mantidos, promovendo a retenção da informação e facilitando a aprendizagem.

O hipertexto: é um recurso que vincula informações adicionais por meio de links, é uma cadeia de informações sem sequiência, ligadas de maneira criativa. Possibilita consultas indexadas de forma direta, instantânea, por meio de elos interativos. Para facilitar o processo de ensino e aprendizagem do conteúdo, tornando mais amigável a interação aluno-aplicação foi incluído, no courseware, um agente pedagógico.

Segundo Silveira (2005), um agente pedagógico é um recurso que permite acrescentar, em um sistema hipermídia, mecanismos que interpretam as percepções do aluno; estabelecem inferências; resolvem problemas e determinam ações. Ou seja, atuam sobre o ambiente/sistema para realizarem um conjunto de tarefas para as quais foram designados/programados. Os agentes pedagógicos trazem uma nova perspectiva aos ambientes de aprendizagem e às aplicações educacionais, adaptam as interações às necessidades dos alunos, ajudando-os a superarem suas dificuldades de aprendizagem. Os agentes devem exibir um comportamento coerente e responder às interações do aluno com a aplicação. 
Segundo Reis (2000), as características inerentes às interações dos agentes pedagógicos são:

- demonstração explicativa - demonstra ao aluno como resolver problemas e executar tarefas (exemplo na aplicação: transformações de base);

- monitoramento explicativo - o aluno pode solicitar ajuda do agente ou interromper uma demonstração (exemplo na aplicação: é o agente X);

- validação - o ambiente/sistema deve permitir que o aluno questione com o objetivo de validar seu nível de compreensão em relação a uma tarefa;

- ensino oportunístico - permite, ao agente, aproveitar oportunidades durante a solução de um problema, para apresentar novos conceitos, quando necessários (exemplo na aplicação: novos conceitos);

- respostas emotivas - é uma característica do agente de representar comportamento emotivo, por meio de expressões faciais (imagens alusivas a sentimentos), motivando e aliviando frustrações do aluno e compartilhando seus sentimentos de vitória ou derrota.

Para projetar o comportamento de um agente, é preciso prever todos os comportamentos possíveis e suas combinações. O que o caracteriza são as interações realizadas com o ambiente/sistema e como são os processos internos, que possibilitam a realização dessas. As interações são ações ou seqüências de ações que o agente realiza no ambiente/sistema.

O desenvolvimento de uma aplicação hipermídia sobre qualquer área, incluindo a educacional, envolve as fases mostradas abaixo:

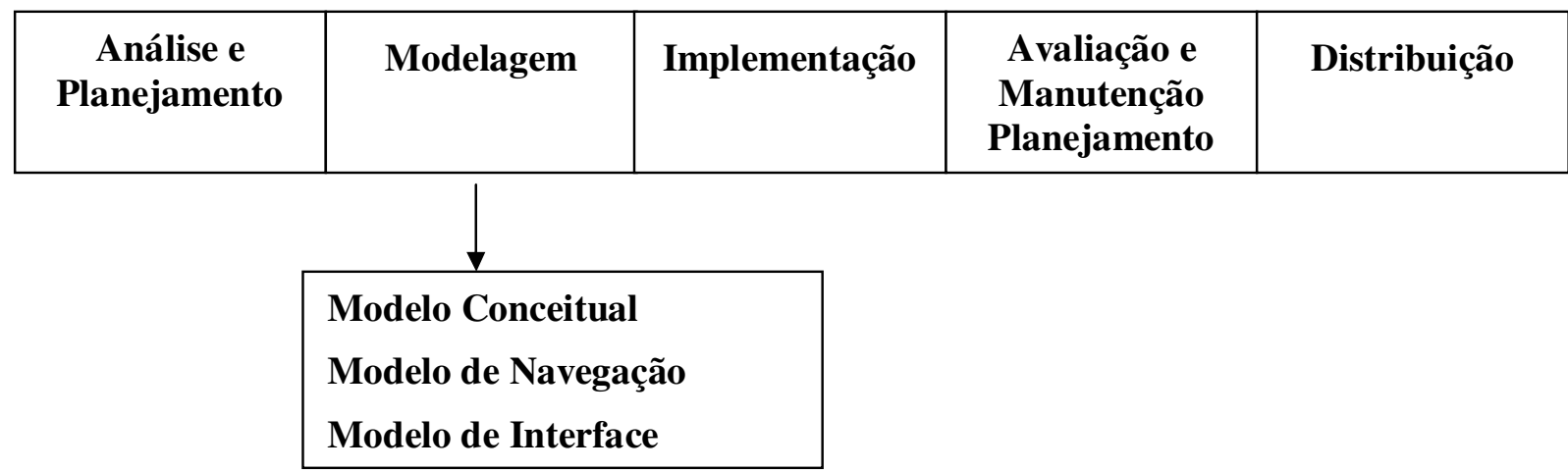

Figura 1: Etapas do desenvolvimento de uma aplicação 
$1^{\circ}$ ) ANÁLISE E PLANEJAMENTO - nessa fase, foi definido o tema e feito o levantamento de aplicações similares. A partir da análise e planejamento, foi definido o objetivo da aplicação e o público alvo. Foram feitas a coleta, a análise e a organização dos conteúdos. A organização obedeceu a um roteiro adequado ao aprendiz, considerando a seqüência dos conteúdos e apresentando a informação de forma didática e pedagógica.

$2^{\circ}$ ) MODELAGEM - Segundo Johnson-Laird, "modelagem é uma técnica que permite a construção de modelos, com o objetivo de facilitar a compreensão, a discussão e a aprovação de um sistema antes da sua construção real" (1983, p. 513).

A fase de modelagem do sistema desenvolvido incluiu a criação dos três modelos: conceitual, de navegação e de interface:

a) Modelo Conceitual - estabeleceu como o conteúdo da aplicação seria disponibilizado ao aluno; detalhou a divisão do conteúdo em unidades e em que mídias seriam exibidas.

b) Modelo de Navegação - definiu as estruturas de acesso, ou seja, como o aluno tem acesso aos conteúdos.

c) Modelo de Interface - estabeleceu o layout das telas em harmonia com o conteúdo e criou a identidade visual da aplicação.

$3^{\circ}$ ) IMPLEMENTAÇÃO - a implementação abrangeu a escolha das mídias e a programação da aplicação, a partir do modelo conceitual.

$4^{\circ}$ ) AVALIAÇÃO E MANUTENÇÃO - foi feita durante todo o processo de desenvolvimento da aplicação.

$5^{\circ}$ ) DISTRIBUIÇÃO - foi criado o módulo de execução e a embalagem do CD com o roteiro de instalação para a distribuição.

\section{CONSTRUÇÃO DO MODELO DA APLICAÇÃO COM STORYBOARD}

O storyboard é uma ferramenta criada para o desenvolvimento de quadros (frames) que compõem uma animação. Porém, seu uso se tornou comum para representar, de maneira informal, na forma gráfica, a rede de nós de uma aplicação V. 6 № 1 , Julho, 2008 


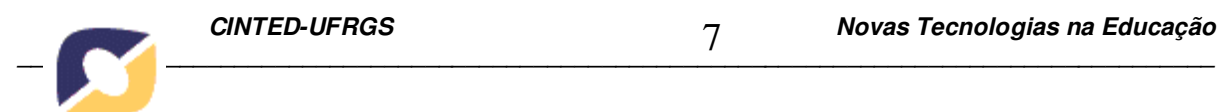

hipermídia. O storyboard pode representar o esboço do modelo conceitual de uma aplicação e mostrar como seus elementos estarão organizados. Permite exibir o planejamento do conteúdo de cada unidade e a disposição das mídias a serem utilizadas. A disposição dos quadros no storyboard mostra as estruturas de acesso, ou seja, como será a navegação dentro da aplicação. O storyboard é um mecanismo de auxílio à implementação.

A partir da modelagem, veio a fase da implementação, na qual foi utilizada um Sistema de Autoria com recursos para integrar todas as mídias em uma estrutura interativa, que permite uma navegação lógica e intuitiva, para que o aluno não se sinta desorientado.

A implementação foi feita com os recursos do Sistema de Autoria TOOLBOOK, versão 7.1. O TOOLBOOK foi desenvolvido pela Asymetrix para a plataforma Windows na década de 90. Como todo Sistema de Autoria trabalha nos modos autor e leitor, a fase de implementação começou com a determinação do tamanho das páginas e com a programação da página padrão, a qual contém a área de navegação com os botões e os objetos compartilhados em todas as páginas.

A partir da implementação foi programada a tela de Apresentação que identifica a aplicação e está em harmonia com o restante da aplicação. Na tela de apresentação, encontra-se a tela Menu que oferece as opções básicas para a navegação dentro da aplicação. Já a tela de Créditos, exibe as informações relacionadas aos recursos utilizados na aplicação. Ao finalizar a implementação, foi gerado o código executável que permite a aplicação ser executada em qualquer equipamento sem o Sistema de Autoria.

Dessa forma, a aplicação hipermídia sobre Sistemas de Numeração permite o ensino individual que promove a independência do aluno, o desenvolvimento da sua habilidade em trabalhar sozinho, segundo seu ritmo e respeitando suas preferências e o processo de aprendizagem.

A aplicação apresenta interfaces gráficas acessíveis, conteúdo teórico com exemplos, animações e simulações dos procedimentos, para a execução das operações e as transformações de bases. Dentre as telas da aplicação, tem-se: tela de apresentação relacionada às opções: Sistema de Numeração; Bases dos Sistemas de Numeração 2, 7 , 


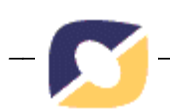

8, 10 e 16; conversão entre os diferentes Sistemas de Numeração; Mudança de Base e Operações.

A seguir, apresentam-se algumas telas que permitem ter uma idéia de como a aplicação foi construída.

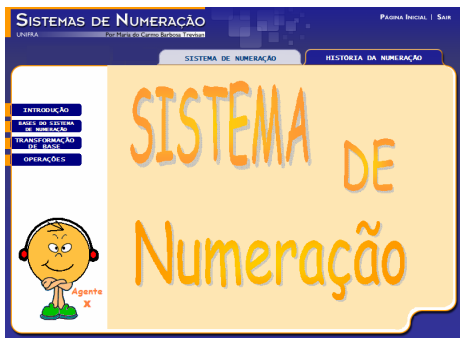

Figura 2: Tela de Apresentação Sistema de Numeração

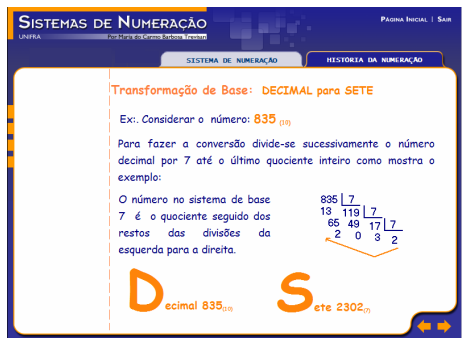

Figura 5: Tela de transformação de base Decimal para Sete.

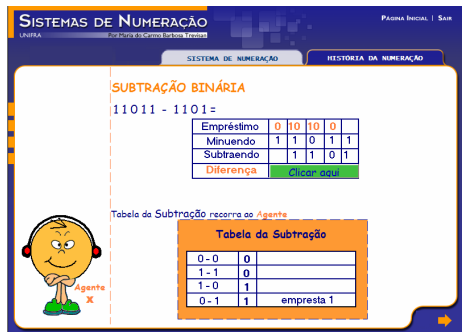

Figura 8: Tela com a operação subtração na base Binária

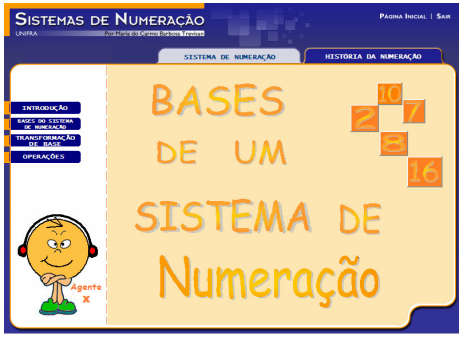

Figura 3: Tela de Apresentação das bases.

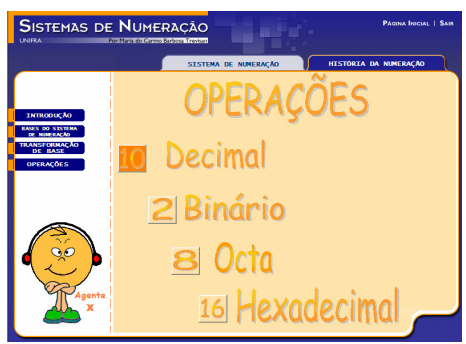

Figura 6: Tela das opções das operações na base decimal.

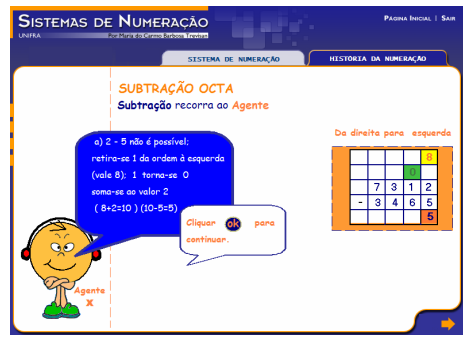

Figura 9: Tela com a operação subtração na base Octa

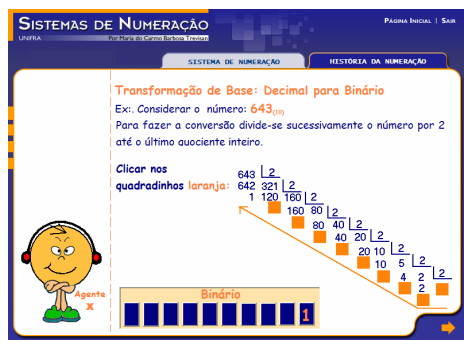

Figura 4: Tela do exemplo de Transformação de base Decimal para Binário.

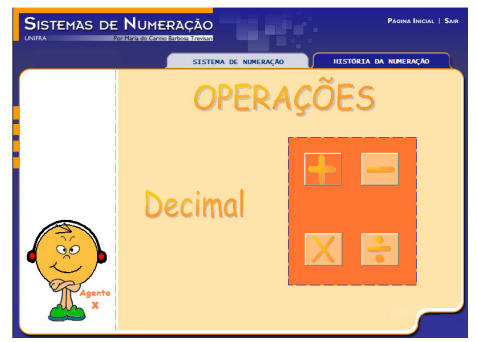

Figura 7: Tela com as opções de operações na base Decimal.

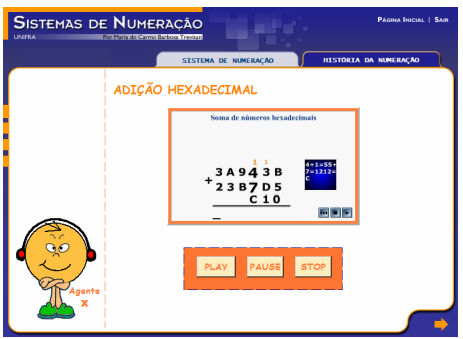

Figura 10: Tela com a operação adição na base Hexadecimal

CONSIDERAÇÕES FINAIS 
O objetivo deste trabalho foi planejar e desenvolver uma aplicação hipermídia sobre Sistemas de Numeração, para ser utilizada como recurso didático no ensino de Sistemas de Numeração e das operações matemáticas nas bases: decimal, binária, octa e hexadecimal, possibilitando a visualização dos processos operativos envolvidos para potencializar a aprendizagem desses conteúdos.

Na navegação, é usada a estratégia do roteiro guiado com o objetivo de permitir ao aluno acessar o conteúdo, obedecendo uma ordem predeterminada. Com isso, os alunos terão segurança na navegação, uma vez que o conteúdo fica disponibilizado, satisfazendo os pré-requisitos necessários para a aprendizagem.

A aplicação permite o uso de um software educacional, para introduzir o tema sobre Sistemas de Numeração; a aplicação inclui os sistemas numéricos de diferentes civilizações; as operações matemáticas, com a simbologia utilizada em cada sistema e a transformação entre diferentes bases.

\section{REFERÊNCIAS BIBLIOGRÁFICAS}

BOYER, CARL B. História da Matemática. Edgard Blücher: São Paulo, 1974.

DALABONA, J. S. Uma reflexão sobre o uso de materiais digitais em atividades de Matemática. Monografia de Especialização em Informática na Educação. Porto Alegre: CINTED-UFRGS, 2005.

FALKEMBACH, G. A. M. Adaptive Hypermedia: an option for the development of educacional systems in order to getting more effective learning. THE INTERNACIONAL CONFERENCE ON NEW TECNOLOGIES IN SCIENCE EDUCATION. Proceedings. Portugal: Aveiro, 2001.

Uma experiência de resolução de problemas através da estratégia ascendente: ambiente de aprendizagem adaptado para algoritmos (A4). Tese de Doutorado em Informática na Educação. Porto Alegre: UFRGS, 2003.

JUNG, C. F. Metodologia para pesquisa e desenvolvimento aplicada a novas tecnologias, produtos e processos. Rio de Janeiro: Axcel Books do Brasil, 2004.

JOHNSON-LAIRD, P. Mental models. Cambridge: Harvard University Press, 1983.

SANCHO, J. M (org.). Para uma Tecnologia Educacional. Porto Alegre: Artes Médicas, 1998. 
SILVEIRA, S. R. Formação de grupos colaborativos em um Ambiente Multiagente Interativo de Aprendizagem na Internet: um estudo de caso utilizando sistemas multiagentes e algoritmos genéticos - Tese de doutorado em Ciência da Computação Porto Alegre: PPGC - UFRGS, 2005.

REIS, A. B. Um modelo do aluno adaptativo para sistemas na Web - Dissertação de Mestrado. Porto Alegre: PPGC - UFRGS, 2000. 